\title{
Specific Features of Biocorrosion of the Circulation Cooling System in the Petrochemical Industry
}

\author{
Anatoly Laptev ${ }^{1, *}$, Oleg Poltarukha ${ }^{2}$, Tatiyana Tourova ${ }^{3}$, Diyana Sokolova ${ }^{3}$, Andrey Golubev ${ }^{1}$ and Ivan Golubev ${ }^{4}$ \\ ${ }^{1}$ LLC “Ufa Technological Enterprise”, Ufa, Russia, 450064, Cosmonauts st., 1, Ufa, Republic of Bashkortostan, Russia \\ ${ }^{2}$ A.N. Severtsov Institute of Ecology and Evolution of the Russian Academy of Sciences, 119071, Leninsky av., 33, Moscow, Russia \\ ${ }^{3}$ Federal Research Centre "Fundamentals of Biotechnology" of the Russian Academy of Sciences, 119071, Leninsky av., 33/2, Moscow, \\ Russia \\ ${ }^{4}$ STC "New Technologies and Materials", Peter the Great St. Petersburg Polytechnic University, 195251, Polytechnicheskaya st., 29, \\ St. Petersburg, Russia
}

\begin{abstract}
The circulating water of the cooling systems of petrochemical enterprises has a number of special features: the temperature of cooling water is in the range of $14-28{ }^{\circ} \mathrm{C}$ all year round, the evaporation of water in cooling towers increases the concentration of dissolved salts. Inevitable ingress of hydrocarbons, dosing of corrosion inhibitors, scaling, reagents for dispersing and softening of the water creates favorable conditions for micro- and macroorganisms development. Existing standards stipulate that the number of viable bacterial cells in planktonic form should not exceed 10 cells $/ \mathrm{ml}$, the number of bacteria in the adhered form is not regulated, nevertheless these organisms in particular lead to biocorrosion. During the assessing of the biological degradation of water cycle equipment materials, it was studied the micro- and macroorganisms that populate the surface of steel samples 20. Studies of the effect of this bacteria on the corrosion of steel 20 showed that this whole complex of micro- and macroorganisms, releasing metabolites into the water, also indirectly affects the processes of corrosion, and when choosing protection methods, it is necessary to take into account not only the presence and types of bacteria, but also the entire local biocenosis.
\end{abstract}

There is a number of specific characteristics of jacket water of cooling systems at petrochemical enterprises that determine development of microorganisms and macroorganisms (living in it). The temperature of cooling water is within the range of $14-28^{\circ} \mathrm{C}$ throughout the year. This temperature range is usually narrower than the one that can be observed in natural temperate waters. There are no long periods of significant decline in water temperature, it does not freeze, which makes it possible for all or most of the bacteria in the cooling systems to grow and reproduce year-round. Furthermore, sufficiently intensive mixing of water contributes to oxygenation of water even under high temperature conditions, when solubility of oxygen in water is substantially lower. This is also beneficial for the development of marine dwellers. Evaporation of water in cooling towers increases concentrations of dissolved salts and suspended mechanical impurities that provides for more favourable living conditions for species that inhabit natural water bodies with increased mineralization. It is widely known that hydrocarbons and other refined products, additives of corrosion inhibitors, scale inhibitors, reagents for dispersion and water demineralization are common for jacket water. On the one hand, these components inhibit development of species that demand water quality, but, on the other hand, they stimulate development of pollutionresistant species (especially if these species are able to consume organics released into water). Various types of oxidizing (sodium hypochlorite, hydrogen peroxide) and nonoxidizing (complex organic compounds) biocides that are released into cooling system water would seem to inhibit development of microorganisms and macroorganisms under these conditions. However, due to stringent environmental standards and labor protection requirements, the amount of biocides is now strictly regulated. Therefore, these components cannot considerably inhibit development of many species that settle under these conditions. Moreover, such limited amounts of biocides can help to select resistant species. Existing regulations (VUTP (industry-specific process engineering guidance) stipulate that the number of viable bacterial cells in planktonic form shall not exceed $10^{3}$ $\mathrm{c} / \mathrm{ml}$, whereas the number of bacteria in adhesive form is not regulated, although these exact organisms cause biocorrosion.

In the course of assessment of biological destruction of equipment materials of water circulation cycle, we studied microorganisms and macroorganisms, which populate the surface of steel 20 samples that are shown in the circulation cooling system of JSC «Ufaorgsintez» (Ufa, Russia) [1-5]. Sampling took place in 10, 20, 40 and 60 days. We found that full-fledged (though limited in variety) communities of macroorganisms are formed in the stagnant zones of a water circulation system. These communities (along with single-celled planktonic algae) included phytophag planktonic crustaceans (members of Calanoida and Cyclopoida) whose species could not be identified due to the absence of adult mature specimens in

\footnotetext{
* Corresponding author: laptev@bk.ru
} 
the test. Though these animals have little direct contact with the prototypes, they indirectly influence the composition of a bacterial-algae film that is formed on their surfaces by producing metabolites into water. Physa fontinalis gastropods (L., 1758) scrape off single-celled organisms that settle various solid surfaces (including prototypes) and remove protective polysaccharides. This exposes the surface of the metal and results in development of differential aeration pairs and intense local corrosion. Numerous detritophagous animals inhabit organically-rich sediments at the bottom of the circulation cooling system. These animals are represented by undefined mosquito larvae of the Chironomidae family (moth), oligochaetes of the Enchytraeidae family, presumably Enchytraeus albidus (Henle, 1837), as well as small crustaceans of Harpacticoida, presumably Canthotus campphylinus (Jurine, 1820). Unlike planktonic crustaceans, detritophagous animals indirectly affect the community of single-cell microorganisms that settle on the surface of prototypes by releasing metabolites. Predatory leech Erpobdella octoculata (L., 1758) is at the top of the food chain in the studied community. This species consumes mainly oligochaetes and Chironomidae larvae. Although this leech in its adulthood swims in the water column and occasionally takes its prey from the surface of the sediments, it lays its egg cocoons on various solid surfaces, including prototypes. Metabolites that are produced under cocoons change the composition of the environment which contributes to the destruction of the metal surface layer and initiates pit corrosion. When determining the structure of bacterial communities on the steel 20 samples by highproductive sequencing of $16 \mathrm{~S}$ rRNA fragments, it was shown that Chryseolinea bacteria predominate at the first stage of exposure. Their proportion considerably decreases during further exposure. Arenimonas bacteria dominate at all stages of exposure. Proportion of Pseudomonas bacteria significantly increases by the end of exposure.

Settlement of bacteria on a solid surface depends on many factors and is a random case. Consequently, probability of encounter, and therefore the success of adhesion, should directly depend on the concentration of micro-organisms in water that surrounds solid surface. The results of $\mathrm{M}$ laboratory experiments $\mathrm{M}$ [6] on Pseudomonas sp marine bacteria confirm this fact. At different stages of crop development, the number of attached bacteria grew along with their concentration in water and duration of experiments. Probability of marine bacteria adhesion is also revealed when analyzing its occurrence on diatoms in plankton as they attach to their surfaces. Fletcher [7] designed a simple but realistic model. According to this model, the rate of bacterial adhesion is directly proportional to the concentration of bacteria in water and the proportion of macroorganism free surface. The experimental data she obtained fitted into this model. In the course of her research, she concluded that bacterial adhesion can be characterized by the same quantitative dependencies as Langmuir adsorption.
It is known, [8] that electrostatic and dispersive (van der Waals) interactions determine physical adhesion. Nevertheless, there are more than ten forces that can participate in physical adhesion [9]. Electrostatic forces are taken into consideration as bacterial cells and most solid surfaces in the aquatic environment are negatively charged and therefore have to push off each other. These forces operate at a relatively long distance. The main problem associated with the application of electrostatic force theory to adhesion is to describe distribution of ions on isolated surfaces and their redistribution when surfaces converge. As such, the release of metabolic products by macroorganisms is of high importance. These products are whether in the form of detritus particles or organic or mineral ions, which may have positive (ammonium ion, amine) or negative (carbonates, hydrocarbonates, and organic ions) charge. The substances released by macroorganisms not only feed a number of bacteria, but also significantly change the surface potential and cause a change in dissolution rate of metal (according to its nature) in the aquatic environment. Ammonia, in particular, significantly alkalizes the environment and modifies propensity of metals (e.g., stainless steels and aluminum alloys) for passivation [10].

Unlike in seawater, activities of multicellular attached organisms are significantly less important in development of biological corrosion in freshwater (including water in circulation cooling system). This is due to the fact that biological diversity of multicellular animals in freshwater is considerably lower. In marine waters, fouling organisms (mainly shellfish, attached polychaete worms, bryozoans, coelenterates, sea squirts, acorn shells, etc.) form a complete (often multilayered) cover on the surface or in various cavities of solid substrate. There are numerous motile associates (even fish) nearby that are closely connected to the fouling community. Some bivalves (e.g., the Dreissenidae), a number of freshwater bryozoans species and larvae form of specific groups of aquatic insects (e.g., the Simuliidae) represent multicellular fouling animals in freshwater. Fouling multicellular organisms rarely form a complete (multilayered, in particular) cover on the surface of a substrate in freshwater. The community with reduced species diversity that we studied in this paper confirms this fact. Only egg cocoons of E. octoculata leeches are the closest to attached organisms.

Thus, the study identified the following crucial factors for steel 20 biocorrosion in circulation cooling system [11-15]:

1) Slime-forming bacteria are the first to settle on the prototype surface and form its protective polysaccharose membrane

2) A formed base creates favourable conditions for sedimentation and subsequent development of a variety of bacteria and microalgae and absorbs mechanical impurities. Organisms that develop there are aerobic ones and virtually prevent oxidation on the contaminated surface areas.

3) Metabolic activity of microalgae and various animals that develop in water and sediments causes development of bacteria, and affects their sedimentation 
and subsequent development on the surface of the samples.

4) A small number of multicellular animals that constantly interact with the surface of the samples influence the developing bacterial membrane. $P$. fontinalis gastropod, for example, scrapes off singlecelled organisms and removes protective polysaccharides, which exposes the surface of metal. It causes production of differential aeration pairs and intensive local corrosion. Due to released metabolites, local environment changes considerably under the egg cocoons that E. octoculata leech lays on the sample surface. It contributes to the destruction of the surface layer of the metal and causes pit corrosion.

5) Not only bacteria but also the entire local biotic communities are to be taken into consideration when choosing methods of protection against corrosion of metallic structures of a circulation cooling system.

The study was carried out with the financial support of the Russian Foundation for Basic Research (grant № 18-29-05033).

\section{References}

1. A.B. Laptev, T.P. Turova, D.Sh. Sokolova, Destruction of Polyesters by Fouling Microorganisms in Aquatic Environment. Modern approaches to the assessment of the impact of external factors on materials and complex technical systems materials of the All-Russian Scientific and Technical Conference, Climate-2019, 212-216 (2019)

2. E.V. Kurchev, E.V. Nikolaev, A.V. Golubev, A.B. Laptev, Biodegradation of Thermoplastic Materials Based on Polyesters in Aquatic Environment of Various Mineralization. Modern approaches to the assessment of the impact of external factors on materials and complex technical systems materials of the All-Russian Scientific and Technical Conference, Climate-2019, 227-232 (2019)

3. Method of Processing Technical Gases and Device. Pat. №2287492, Russian Federation, № 2005128408/15; declared. 01.09.2005; pub. 20.11.2006, Byul. № 32, 16 pp.

4. Method of Corrosive Environment Treatment. Pat. №2293707, Russian Federation, № 2005128408/15; declared. 01.09.2005; pub. 20.02.2007, Byul. № 3 p. 25

5. A.B. Laptev, E.V. Nikolaev, E.V. Kurchev, Yu.S. Goryashnik, Features of Biodegradation of Thermoplastics Based on Polyesters in Different Climatic Zones. Electronic scientific journal "Proceedings of VIAM", 7 (79), 84-91 (2019)

6. A.M. Kogan, E.V. Nikolaev, A.V. Golubev, A.B. Laptev, D.A. Movenko, Stages of Biofouling and Corrosion of Steel in the Black Sea Water, 6 (78), 8394 (2019)

7. A.I. Railkin, Colonization of solid bodies by benthic organisms, 427 (Publishing House of St Petersburg University, St. Petersburg, 2008)
8. Fletcher, The Effect of Culture Concentration and Age, Time, Temperature on Bacterial Attachment to Polystyrene. Can.J.Microbial, 23 (1), 1-6 (1977)

9. D. Vague, C.M. Duarte, C. Marrise, Phytoplancton Colonization by Bacteria Encounter Probability as a Limiting Factor. Marine ecology programm series, 54 (1-2), 137-140 (1989)

10. M. Fletcher, Bacterial ahesion: mechanism and fisiological Significance, 476 (Plenum Press, New York, London, 1985)

11. B.S. Ermakov, A.A. Alhimenko, N.O. Shaposhnikov, A.S. Tsvetkov, A.V. Shirokov, Study of the crystallographic texture of pipe steel. Letters on Materials, 10 (1), 48-53

12. B.V. Derjaguin, Selected works of Derjaguin B.V. Vol.1. Surface forces in Thin films and Disperse systems. Progress in surface science, 40, 465 (1992)

13. A. Lips, N.E. Jessup, Colloidal aspects of bacterial adhesion. Adhesion of microorganism to Sufases, 527 (Acad Press, London et all, 1979)

14. A.B. Laptev, A.V. Golubev, D.M. Kireev, E.V. Nikolaev, To the Question of Biodegradation of Polymeric Materials in Natural Environments. Electronic scientific journal "Proceedings of VIAM", 9 (81), 100-107 (2019)

15. D.R. Latypova, O.R. Latypov, D.E. Bugai, Influence of electrode potential on the depth of pitting corrosion in the surface structures of placed steel. Nanotehnologii v stroitel'stve (Nanotechnologies in Construction), 10 (3), 167-178 (2018) 